\title{
The role of sound and spelling in auditory word recognition: Further evidence from brain-damaged patients
}

\section{Shari R. Baum \& Carol L. Leonard}

To cite this article: Shari R. Baum \& Carol L. Leonard (2000) The role of sound and spelling in auditory word recognition: Further evidence from brain-damaged patients, Aphasiology, 14:10, 1055-1063, DOI: $10.1080 / 02687030050156601$

To link to this article: http://dx.doi.org/10.1080/02687030050156601

曲 Published online: 31 Aug 2010.

Submit your article to this journal $\llbracket$

Џ Article views: 27

Q View related articles $\sqsubset$ 


\title{
The role of sound and spelling in auditory word recognition: Further evidence from brain-damaged patients
}

\author{
SHARI R. B A UM and CAROL L. LEONARD \\ School of Communication Sciences \& Disorders, McGill University, Montreal, \\ Canada
}

(Received 8 July 1999; accepted 16 January 2000)

\begin{abstract}
This follow-up investigation explored the effects of phonological and orthographic relatedness on auditory lexical access in left- and right-hemisphere-damaged individuals. Participants listened to prime-target pairs that shared word-initial phonology (e.g., definite-deaf), initial orthography (e.g., logic-log), both initial phonology and orthography (e.g., message-mess), or were unrelated (e.g., castlegreen), presented at two different inter-stimulus intervals. All groups of subjects demonstrated facilitation of lexical decision latencies due to the combined influence of both orthography and phonology, confirming earlier findings concerning rime relations. The findings are briefly discussed in relation to the neural representation of formal lexical codes.
\end{abstract}

Recent investigations focusing on the activation of the formal properties of lexical items in brain-damaged individuals have yielded a number of interesting findings. In particular, Milberg et al. (1988a, b) found that nonfluent (Broca's) aphasic patients were more sensitive than normal controls to phonological distortion in activating related word candidates; that is, the nonfluent aphasic patients did not exhibit phonologically mediated priming (e.g., gat-(cat)-dog). In contrast, the fluent aphasic patients tested displayed greater than normal mediated priming, suggesting they were less sensitive to phonological distortion and may have overactivated phonologically related word candidates (Milberg et al. 1988a, b). Not surprisingly, these findings suggest that different regions within the left hemisphere play important roles in lexical access via phonological codes (see also Gordon and Baum 1994, Baum 1997).

Studies have also examined the role of the right hemisphere in processing lexical form. For example, Leonard and Baum (1997) tested a hypothesis proposed by Zecker and colleagues (1986) which claimed that orthographic effects in auditory lexical access are lateralized to the left hemisphere. Individuals with left hemisphere damage (LHD), including fluent and nonfluent aphasics, and individuals with right hemisphere damage (RHD) were compared to normal controls performing an auditory lexical decision task tapping phonological and orthographic priming effects. Leonard and Baum (1997) reported that lexical decision latencies to target words that were both phonologically and 
orthographically related to their primes (in terms of rime relations; e.g., lord-cord) were facilitated relative to unrelated stimuli (e.g., bill-tent). Of particular note was the finding that this pattern of results held for all groups tested. Also of interest was an interference effect of orthographic relatedness alone (i.e., slower reaction times to target words that were only orthographically related to the prime, e.g., touch-couch, relative to unrelated words; see also Zecker et al 1986; but cf. Burton et al. 1993). Because both of these results held across subject groups, Leonard and Baum (1997) concluded that orthographic effects emerge independent of brain damage.

To further assess the role of orthography in auditory word recognition, Baum and Leonard (1999) conducted a follow-up investigation in which inter-stimulus intervals were manipulated in an effort to tap more automatic and more strategic processing independently. The results of this experiment confirmed Leonard and Baum's (1997) earlier findings of orthographic and phonological effects in auditory lexical access irrespective of brain damage. Moreover, the findings suggested that orthographic effects tend to be largely strategic in nature, emerging in a long $(750 \mathrm{~ms})$ but not short $(100$ $\mathrm{ms}$ ) inter-stimulus interval (ISI) condition. The results of both studies failed to support the overactivation of lexical candidates in fluent aphasic patients postulated by Milberg and colleagues (1988b), but were suggestive of a possible weakened activation or fast decay of activation in nonfluent aphasic patients (see also Milberg et al. 1988b; Milberg et al. 1995; cf. Hagoort 1997, Prather et al. 1997).

All of the studies described have focused on rime relations; however, the importance of word-initial information in auditory lexical access cannot be underestimated (e.g., Marslen-Wilson 1989). In an attempt to confirm our earlier findings and extend the results to word-initial properties, the present study was undertaken. Following Jakimik et al. (1985), pairs of words were created that shared initial phonology and orthography (e.g., message-mess), initial phonology alone (e.g., definite-deaf), initial orthography alone (e.g., logic-log), and no formal properties (e.g., castle-green). In normal subjects, Jakimik et al. (1985) found facilitation for lexical decisions when the prime and target words shared both phonology and orthography, but not when only one property was shared. Their findings confirmed that orthographic information is activated as a consequence of auditory word recognition and that word-initial properties facilitate activation as do rime properties; however, the data did not directly address whether this activation was a result of automatic or strategic processes or whether such activation was lateralized to the right or left hemisphere. Thus, the present investigation includes groups of LHD and RHD patients as well as normal controls in two experimental conditions that vary in the degree to which they tap automatic and strategic processing.

\section{Methods}

\section{Subjects}

Four groups of subjects participated in this experiment: 10 left-hemisphere-damaged (LHD) nonfluent aphasic patients, 7 LHD fluent aphasic patients, 11 right-hemispheredamaged (RHD) patients, and 12 age- and education-matched non-neurologically damaged control subjects. All were native speakers of English who passed a hearing screening at $<35 \mathrm{~dB} H \mathrm{HL}$ at the speech frequencies $(.5,1$, and $2 \mathrm{kHz})$ in the better ear. All brain-damaged patients had experienced a single, unilateral infarct due to cerebrovascular accident (CVA) (confirmed by CT or MRI) at least four months prior to testing. The LHD subjects underwent a battery of language tests including subtests of 
the Psycholinguistic Assessment of Language (Caplan 1992) and the Boston Diagnostic Aphasia Examination (Goodglass and Kaplan 1983) and were diagnosed according to results of these tests and clinical records. A test battery assessing comprehension of figurative language, inference generation, and emotional prosody was performed for the RHD patients. Background information on all of the participants may be found in table 1 .

\section{Stimuli}

The experimental stimuli included 30 pairs of words in each of four conditions: (a) pairs sharing both orthography and phonology of the initial CVC sequence (e.g., messagemess) (OP); (b) pairs sharing phonology alone (e.g., definite-deaf) (PR); c) pairs sharing orthography alone (e.g., logic-log) (OR); and (d) unrelated pairs (e.g., castle-green) (UN). Stimuli were derived from those used by Jakimik and colleagues (1985) in order to parallel their design as closely as possible, and all carried stress on the first syllable. Each experimental pair consisted of a multisyllabic prime word (two or three syllables) followed by a monosyllabic target word. Across conditions, target words were matched for mean frequency of occurrence, with all mean frequencies $>100$ per million (Francis \& Kucera, 1982). In addition, 120 prime-target pairs with non-word targets were included to balance word and non-word responses on the lexical decision task. Half of these $(n=60)$ were designed to parallel the related conditions with word targets (i.e., 20 orthographically and phonologically related, 20 phonologically related, 20 orthographically related); the remaining 60 non-word trials included unrelated targets.

The stimuli were recorded onto tape individually by an adult male speaker of English in random order, and were digitized at a rate of $10 \mathrm{k}$ samples per second with a $4.5 \mathrm{kHz}$ low-pass filter and 12-bit quantization using the BLISS speech analysis system (Mertus 1989). Primes and targets were paired with two different inter-stimulus intervals (ISI, measured from prime offset to target onset) $-100 \mathrm{~ms}$ and $750 \mathrm{~ms}-$ in an effort to tap more automatic and more controlled processing in the two conditions. The inter-trial interval was 5 seconds.

\section{Procedure}

Within ISI condition, stimuli were presented to individual subjects by computer in a fixed random order over closed headphones. Subjects were seated in front of a response board with buttons labelled 'yes' and 'no' and were instructed to decide as quickly and accurately as possible whether the second word in each pair was a real word in English. All subjects used their (currently) dominant hand for response, resting it equidistantly between the 'yes' and 'no' buttons between trials. A series of eight practice trials preceded each experiment to accustom subjects to the task. The stimuli for the two ISI conditions were presented in different sessions, separated by at least one week, with the order of presentation counterbalanced across subjects within each group. Responses and reaction times $(\mathrm{RT})$ were recorded by the computer.

\section{Results}

\section{$100 \mathrm{~ms}$ ISI condition}

Mean lexical decision latencies were computed for each subject in each condition for correct responses to word targets only. In addition, outliers more than two standard deviations from the mean for each condition were excluded from analysis. Average RTs 


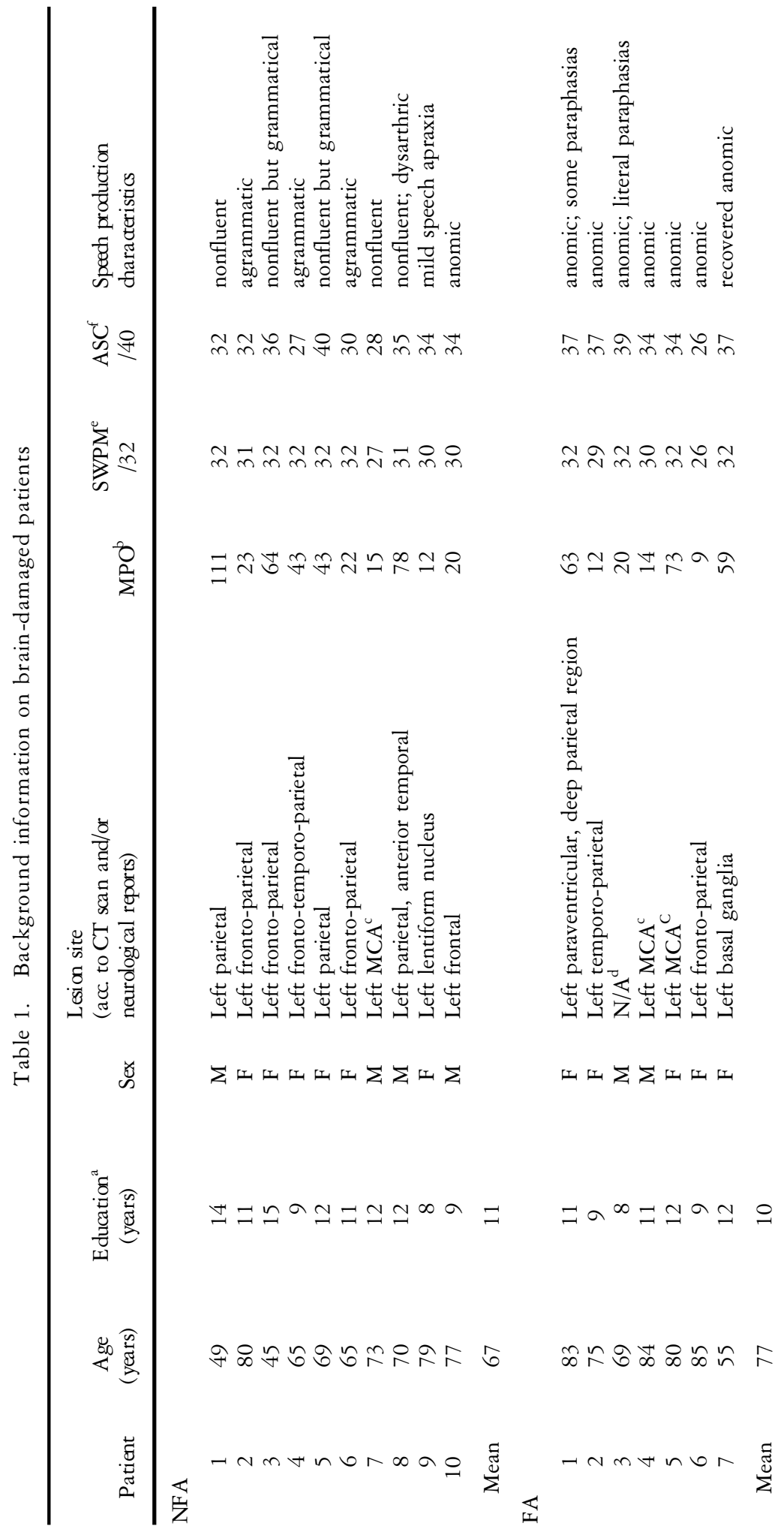


节

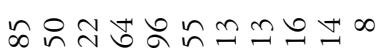

8

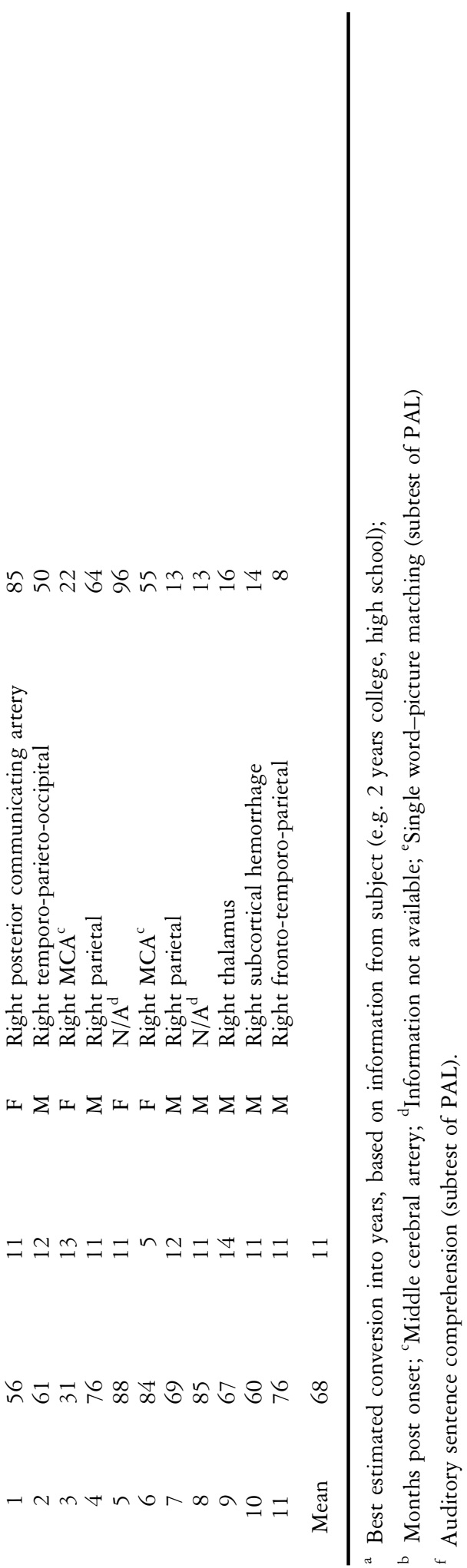




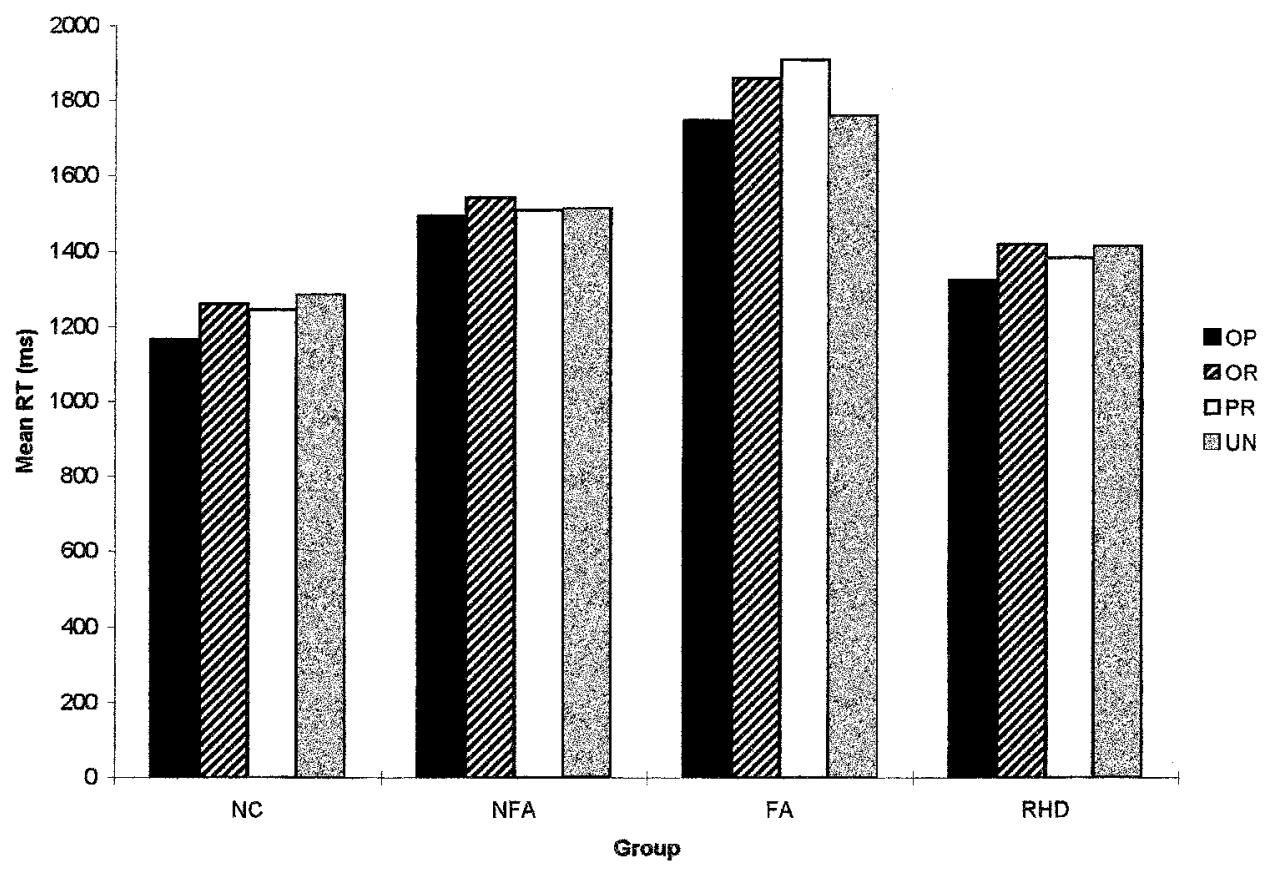

Figure 1. Mean RT according to Prime Type by Group at $100 \mathrm{~ms}$ ISI. NC $=$ normal control group, NFA $=$ nonfluent aphasic group, FA $=$ fluent aphasic group, $\mathrm{RHD}=$ right-hemispheredamaged group.

for each group in each experimental condition are displayed in figure 1. As may be seen, the pattern across conditions for each group was similar, with fastest RTs in the OP condition. A Group $\times$ Prime Type analysis of variance (ANOVA) was conducted on the logarithm of mean reaction times by both subjects $\left(\mathrm{F}_{1}\right)$ and items $\left(\mathrm{F}_{2}\right)^{1}$. The ANOVA revealed a main effect for Group, $\mathrm{F}_{1}(3,34)=3.86, \mathrm{p}<.05 ; \mathrm{F}_{2}(3,348)=121.4$, $\mathrm{p}$ $<.001$, and a main effect for Prime Type, $\mathrm{F}_{1}(3,102)=4.08, \mathrm{p}<.01$, which did not reach significance by items, $\mathrm{F}_{2}(3,116)=1.7, \mathrm{p}=.17$. Post hoc analysis using the Newman-Keuls procedure $(\mathrm{p}<.05)$ revealed that the fluent aphasic group displayed significantly slower RTs than the normal and RHD groups who did not differ from each other; the nonfluent aphasic group's RTs did not differ from those of any other group. The main effect of Prime Type was accounted for by significantly faster RTs in the OP condition (mean $=1433 \mathrm{~ms}$ ) relative to all others, which did not differ from one another $(\mathrm{OR}$ mean $=1522 \mathrm{~ms}$; PR mean $=1513 \mathrm{~ms} ; \mathrm{UN}$ mean $=1494 \mathrm{~ms})$.

In examining the individual data, it is interesting to note that $83 \%$ of the subjects in the normal control group displayed the group pattern of shorter RTs in the OP relative to the UN condition. In contrast, a smaller number of subjects in each of the braindamaged groups demonstrated patterns conforming to that of the group as a whole (RHD: 70\%; nonfluent aphasics: 50\%; fluent aphasics: 33\%). These findings suggest that individuals in the brain-damaged groups were less sensitive than normal to the facilitory effects of the combined orthographic and phonological overlap.

\footnotetext{
${ }^{1}$ One fluent aphasic patient and one RHD subject did not complete this condition.
} 


\section{$750 \mathrm{~ms}$ ISI condition}

Mean lexical decision latencies for the longer ISI condition (computed as described earlier) are illustrated in figure 2. As is clear from the figure, the pattern of RTs was quite comparable to that found for the short ISI condition. A Group $\times$ Prime Type ANOVA revealed only a main effect for Prime Type, $\mathrm{F}_{1}(3,108)=5.6, \mathrm{p}<.01$, which did not quite reach significance in the item analysis, $\mathrm{F}_{2}(3,116)=2.15, \mathrm{p}=.098$. As in the short ISI condition, RTs in the OP condition (mean $=1333 \mathrm{~ms}$ ) were significantly faster than all others, which did not differ from one another $(\mathrm{OR}$ mean $=1437 \mathrm{~ms}$; PR mean $=$ $1431 \mathrm{~ms}$; UN mean $=1410 \mathrm{~ms}$ ). As in the $100 \mathrm{~ms}$ ISI condition, an examination of individual data revealed that the large majority of subjects in the normal control group (92\%) exhibited the group pattern of shorter latencies in the OP relative to the UN condition. The pattern was less consistent in the brain-damaged groups, with only $55 \%$, $50 \%$, and $71 \%$ of the RHD, nonfluent aphasic, and fluent aphasic subjects, respectively, showing the group pattern. Interestingly, a larger proportion of the fluent aphasic group demonstrated facilitation in the $750 \mathrm{~ms}$ condition compared to the $100 \mathrm{~ms}$ condition ( $71 \%$ vs $33 \%$ respectively).

\section{Discussion}

The findings of the present investigation are largely consistent with our previous results which indicated that the combined influence of phonological and orthographic relatedness facilitates auditory lexical access in listeners, regardless of presence or site of brain

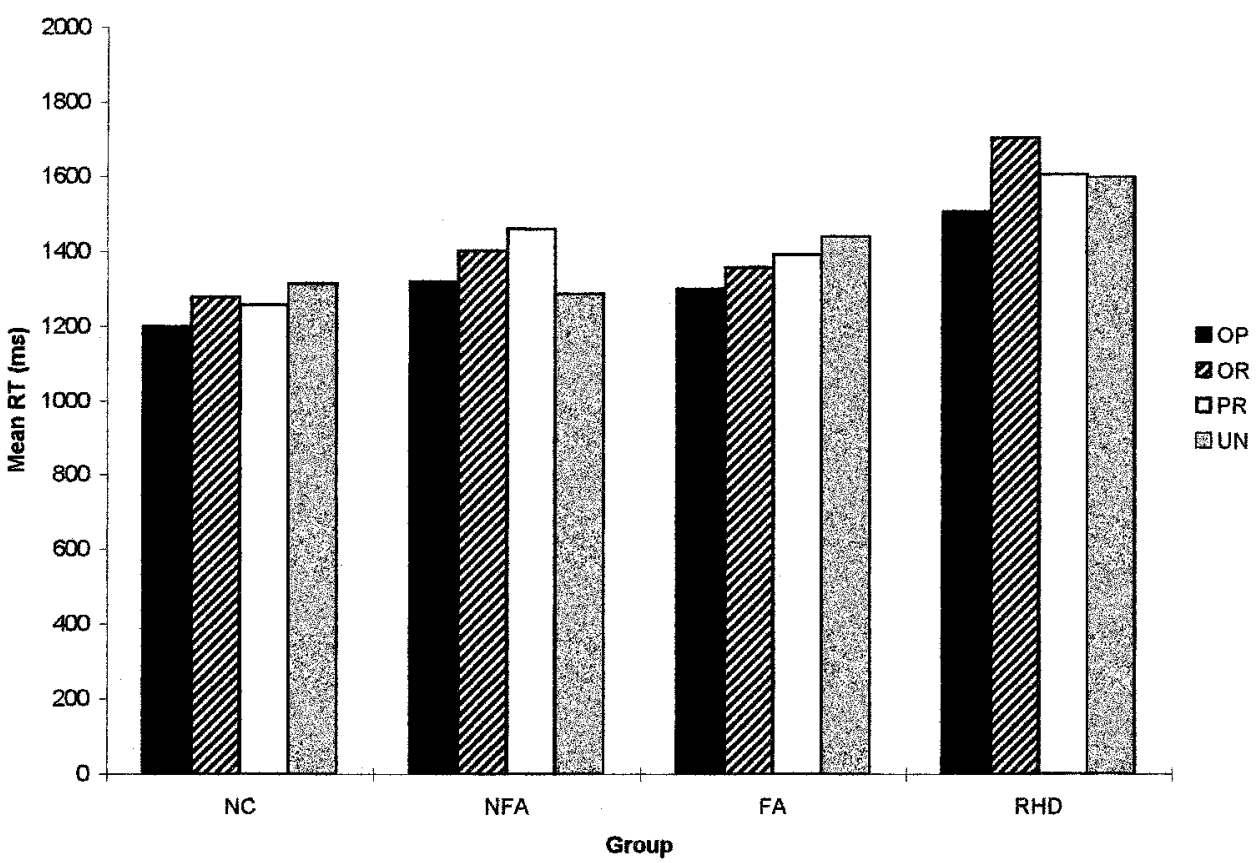

Figure 2. Mean RT according to Prime Type by Group at $750 \mathrm{~ms}$ ISI. NC $=$ normal control group, $\mathrm{NFA}=$ nonfluent aphasic group, $\mathrm{FA}=$ fluent aphasic group, $\mathrm{RHD}=$ right-hemispheredamaged group. 
damage (Leonard and Baum 1997, Baum and Leonard 1999). That is, as shown by Jakimik and colleagues (1985) with young normal adults, lexical decision reaction times were significantly faster in the OP condition relative to the UN condition at both ISIs for all subject groups. These data again provide no evidence that orthographic effects in auditory word recognition are lateralized to the left hemisphere.

In contrast to our earlier findings concerning rime relations (Leonard and Baum 1997, Baum and Leonard 1999), but in keeping with the data of Jakimik et al. (1985), neither phonological nor othographic relatedness alone influenced lexical decision latencies under either ISI condition. It is not entirely clear why such differences would emerge in processing rime and word-initial properties but it must be noted that in our earlier work (Leonard and Baum 1997, Baum and Leonard 1999), both prime and target were monosyllables, whereas in the present investigation, the primes were all polysyllabic words preceding monosyllabic targets. As a result, a different pattern of activation and suppression of word candidates may have occurred. For example, in the OP condition, both phonological and orthographic information activate the same candidates; upon hearing the vowel of the second syllable of the prime (e.g., message), the related monosyllabic target (e.g., mess) may begin to be suppressed (although due to the high degree of overlap, suppression may be weak). In contrast, in the OR condition, the inconsistency between prime and target occurs slightly earlier, upon hearing the initial consonant of the second syllable (or the final consonant of the first, depending on syllabification; e.g., logic-log). Suppression of the target may thus occur earlier and more strongly due to the inconsistent phonological form between prime and target, yielding slower RTs than in the OP condition. It is somewhat surprising that no interference effect was found for the OR condition at the long ISI (cf. Leonard and Baum 1997, Baum and Leonard 1999). There is no obvious explanation for this discrepency at present, but the different nature of the stimuli (i.e., initial versus final overlap) may play some role.

In the PR condition, the absence of priming may have, at least in part, a different source. Although the prime and target diverge at the same point as in the OP condition (i.e., at the vowel of the second syllable), two factors may be at play in yielding increased RTs in the PR relative to the OP condition. First, as in the OR condition, suppression may be stronger due to the orthographic mismatch between prime and target. In addition, it is possible that, upon hearing the target, listeners reactivate the spelling associated with the prime (e.g., DEF for "deaf') which would lead to an incorrect (negative) lexical decision (see Jakimik et al. 1985 for quantitative and anecdotal data based on subjects' self-reports in this regard). Recovering from that garden path may require additional processing time. Although a similar argument could be advanced in the case of rime relations (e.g., tooth-youth), it may be less likely due to the lack of a match at word onset and only a partial syllable match in the rime case (i.e., VC), as compared to a full CVC match in the case of the word-initial relations in the current experiment.

As noted earlier, one of the interesting results of the present study was the failure to find an interaction between Group and Prime Type. Yet, in examining patterns of individual performance, the facilitation found in the OP condition was much less consistent in the LHD aphasic groups. These results suggest that a careful analysis of lesion site and functional deficit in individual brain-damaged participants may yield insights into the neural substrates for the processing of lexical form information.

In sum, this brief follow-up investigation supports the claim that orthographic information is activated in auditory lexical access and that neither LH nor RH brain 
damage consistently interfered with such activation. The findings are not in keeping with Milberg et al.'s (1988b) contention that fluent aphasic patients overactivate lexical items, but differences in the composition of subject groups may account for the inconsistent patterns. Future analysis of individual patients' neuroradiological and behavioural data may better elucidate the relationship between specific brain regions and the processes of auditory word recognition.

\section{Note}

Current affiliation of Carol L. Leonard: Kunin-Lunenfeld Applied Research Unit, Baycrest Centre for Geriatric Care and Dept. of Speech-Language Pathology, University of Toronto, Canada.

\section{Acknowledgements}

This research was supported by a team grant from the Fonds pour la Formation de Chercheurs et l'Aide à la Recherche (FCAR) du Québec.

\section{References}

Baum, S. (1997). Phonological, semantic, and mediated priming in aphasia. Brain \& Language, 60, 347-359.

Baum, S., and Leonard, C. (1999). Automatic versus strategic effects of phonology and orthography on auditory lexical access in brain-damaged patients as a function of interstimulus interval. Cortex, 35, 647-660.

Burton, M., Jongman, A., and Sereno, J. (1993). Phonological and orthographic priming effects in auditory and visual word recognition. Paper presented at the $34^{\text {th }}$ Annual Meeting of the Psychonomics Society, Washington, DC.

Caplan, D. (1992). Language: Structure, process, and disorders (Cambridge, MA: MIT Press).

Francis, W.N., \& Kucera, H. (1982). Frequency analysis of English usage(Boston, MA: Houghton Mifflin.

Goodglass, H., and Kaplan, E. (1983). The assessment of aphasia and related disorders (Philadelphia, PA: Lea \& Febiger).

Gordon, J., and Baum, S. (1994). Rhyme priming in aphasia: The role of phonology in lexical access. Brain \& Language, 47, 661-683.

Jakimik, J., Cole, R., and Rudnicky, A. (1985). Sound and spelling in spoken word recog nition. Journal of Memory \& Language, 24, 165-178.

Hagoort, P. (1997). Semantic priming in Broca's aphasics at a short SOA: No support for an automatic access deficit. Brain \& Language, 56, 287-300.

Leonard, C., and Baum, S. (1997). The influence of phonological and orthographic information on auditory lexical access in brain-damaged patients: A preliminary investigation. Aphasiology, 11, 1031-1041.

Marslen-Wilson, W. (1989). Access and integration: Projecting sound onto meaning. In: W. MarslenWilson (Ed.) Lexical representation and process (Cambridge, MA: MIT Press).

Mertus, J. (1989). BLISS user's manual (Providence, RI: Brown University).

Milberg, W., Blumstein, S., and Dworetzky, B. (1988a). Phonological factors in lexical access: Evidence from an auditory lexical decision task. Bulletin of the Psydonomic Society, 26, 305-308.

Milberg, W., Blumstein, S., and Dworetzky, B. (1988b). Phonological processing and lexical access in aphasia. Brain \& Language, 34, 279-293.

Milberg, W., Blumstein, S., Katz, D., Gershberg, F., and Brown, T. (1995). Semantic facilitaion in aphasia: Effects of time and expectancy. Journal of Cognitive Neuroscience, 7, 33-50.

Prather, P., Zurif, E., Love, T., and Brownell, H. (1997). Speed of lexical activation in nonfluent Broca's aphasia and fluent Wernicke's aphasia. Brain \& Language, 59, 391-411.

Zecker, S., Tanenhaus, M., Alderman, L., and Siqueland, L. (1986). Lateralization of lexical codes in auditory word recognition. Brain \& Language, 29, 372-389. 